\title{
PERAN BUDAYA ORGANISASI DAN EFIKASI DIRI UNTUK MENENTUKAN KEPUASAAN KERJA KARYAWAN
}

\author{
Didit Darmawan \\ Universitas Mayjen Sungkono \\ dr.diditdarmawan@gmail.com
}

\begin{abstract}
Abstrak
Tujuan penelitian ini untuk mengetahui mengetahui pengaruh budaya organisasi dan efikasi diri terhadap kepuasan kerja karyawan. Sebuah organisasi sangat perlu membangun budaya organisasi untuk mempertahankan posisinya di pasar. Budaya organisasi dapat memberi dukungan pada organisasi dan membawa perbaikan terus-menerus, selain itu budaya organisasi juga berdampak pada retensi karyawan. Tingkat efikasi diri yang tinggi dari karyawan membuka peluang pengembangan berkelanjutan di masa depan bagi individu maupun organisasi. Efikasi diri dapat mengantar kepada karyawan untuk dapat bekerja dengan mudah dan mandiri tanpa merasa terbebani. Setiap organisasi menginginkan karyawan dengan efikasi diri yang tinggi karena sangat penting bagi efektivitas organisasi. Karyawan yang optimis akan bisa membawa pada peningkatan kinerja dan produktivitas. Hal yang memenuhi harapan karyawan merupakan landasan dasar membentuk kepuasan kerja. Data primer diperoleh melalui kuesioner kepada karyawan PT X Surabaya yang berjumlah 86 orang dengan menggunakan sampel jenuh. Hasil analisis data adalah analisis regresi linear berganda dengan bantuan program SPSS 26.0 diperoleh nilai signifikan $0,000<0,05$ menunjukkan arti bahwa variabel bebas (budaya organisasi dan efikasi diri) secara simultan memiliki pengaruh signifikan terhadap variabel terikat (kepuasan kerja) selain itu berdasarkan persamaan regresi menunjukkan variabel efikasi diri menjadi variabel yang berpengaruh dominan terhadap kepuasan kerja.
\end{abstract}

Kata Kunci: Budaya Organisasi, Efikasi Diri, Kepuasan Kerja.

\section{PENDAHULUAN}

Setiap perusahaan dituntut untuk meningkatkan kinerja individu dan organisasi secara terus menerus. Pemegang kebijakan dan para manajer harus mempersiapkan sistem dengan paradigma luas dan visioner agar mampu beradaptasi dengan segala dinamika perubahan. Faktor produksi berupa sumber daya manusia merupakan aset berharga bagi proses menjalankan sistem. Sistem kerja dan sistem nilai memiliki peran terhadap sikap dan perilaku kerja karyawan. Salah satu sistem nilai adalah budaya organisasi.

Budaya organisasi sebagai seperangkat sistem nilai yang berbeda yang dapat membantu organisasi untuk menjalankan dirinya sendiri dan menjalankan bisnis yang sukses (Schhneider dan Reichers, 1983). Variabel budaya organisasi memiliki daya tarik untuk diteliti lebih lanjut karena setiap organisasi sebagian besar didasarkan pada pengaruh psikologis dan rasa ingin tahu bagaimana budaya organisasi memengaruhi keputusan manajerial (Pettigrew, 1979; Darmawan, 2007). Sementara itu, tingkat budaya organisasi yang berbeda didasarkan pada kepercayaan, nilai, ritual, dan cerita masa lalu organisasi yang berbeda. Dengan pondasi dasar budaya organisasi tersebut, variabel ini memiliki kontribusi terhadap kebijakan internal organisasi, juga memengaruhi komitmen karyawan terhadap tujuan dan nilai-nilai organisasi, meningkatkan keinginan karyawan untuk memberikan segala upaya menghasilkan kinerja terbaik. Budaya organisasi memengaruhi orang yang berbeda secara berbeda karena cara mereka secara sadar dan tidak sadar berpikir dan, membuat keputusan, itu semua karena apa yang mereka rasakan dan apa yang mereka rasakan dan lakukan setelah merasakannya (Lok dan Crawford, 2004). Perilaku manajemen dan lingkungan yang dapat dipercaya dapat dipertahankan dan juga dipengaruhi oleh ketidakpastian dalam sistem ekonomi, individualisme yang tinggi hal ini berdampak negatif pada kinerja karyawan. Jika budaya organisasi menciptakan masalah seperti kesulitan dalam perubahan, menciptakan hambatan terhadap keragaman maka budaya organisasi itu adalah kewajiban bagi organisasi itu (Robbins dan Judge, 2009). Keberadaan budaya organisasi akan membantu karyawan untuk meningkatkan kinerja individu (Santosa, 2002). Karyawan juga akan memahami fungsi organisasi dengan berbagi norma, nilai dan aturan serta regulasi organisasi melalui pemahaman budaya (Deshpande dan Webster, 1989). Selain itu, karyawan organisasi yang memiliki pemahaman yang lebih dengan budaya organisasi akan cenderung memiliki kepuasan kerja yang lebih (Chang dan Lee, 2007). Menurut Tumbeleka et al. (2016), budaya organisasi 
berpengaruh signifikan terhadap kepuasaan kerja. Setiap anggota baru organisasi atau karyawan baru harus diberikan sosisalisasi terhadap dasar-dasar budaya organisasi atau mereka akan memahami secara berlahan melalui proses waktu dan pembelajaran karena hal tersebut akan memperkuat loyalitas kerja (Darmawan, 2010). Karyawan yang telah terlibat lebih jauh dengan organisasi seharusnya melakukan penyesuaian terhadap budaya organisasi agar nilai-nilai organisasi seiring dengan nilai-nilai diri. Salah satu nilai diri yang perlu dikembangkan adalah efikasi diri.

Salah satu luaran dari efikasi diri yang tinggi dari karyawan adalah kemampuan untuk memanfaatkan dan menghasilkan sumber daya dengan lebih baik di lingkungan kerja mereka untuk menangani tugas-tugas yang menuntut (Heuven et al., 2006). Dari perspektif teori kognitif sosial, perilaku yang diarahkan pada tujuan dipengaruhi oleh efikasi diri, harapan pencapaian tertentu serta dukungan lingkungan dan sumber daya (Lent dan Brown, 2006). Efikasi diri adalah prediktor penting dari penyesuaian dan sejauh mana karyawan menggunakan strategi perilaku afektif. Individu menilai kemampuan mereka untuk berhasil mengatasi tantangan baru sehingga mengembangkan keyakinan efikasi diri domain-spesifik (Raghuram et al., 2003). Individu dengan efikasi diri yang tinggi menangani lebih efektif kesulitan dan lebih mungkin untuk mencapai hasil yang dihargai melalui ketekunan, dan dengan demikian memperoleh kepuasan intrinsik dari pekerjaan mereka. Oleh karena itu, mereka yang memiliki efikasi diri umum yang lebih tinggi cenderung lebih puas dengan pekerjaan mereka (Luthans et al., 2006).

Indikasi keberadaan budaya organisasi yang kuat melekat para kebanyakan karyawan dan masingmasing karyawan memiliki efikasi diri yang cukup tinggi terjadi di salah satu perusahaan logistik yang dengan alasan tertentu disebut dengan PT. X. Perusahaan X merupakan perusahaan swasta yang bergerak di bidang jasa penyewaan dan pengelolaan gudang serta proses pengiriman barang. Perusahaan yang digunakan di penelitian ini merupakan salah satu kantor dari PT. X yang berada di Kota Surabaya. Studi ini akan mengkaji dan mengetahui pengaruh variabel budaya organisasi dan efikasi diri terhadap kepuasan kerja karyawan di perusahaan tersebut.

\section{LANDASAN TEORI DAN PENGEMBANGAN HIPOTESIS Budaya Organisasi}

Menurut Ravasi dan Schultz (2006), budaya organisasi adalah seperangkat asumsi bersama yang memandu apa yang terjadi di organisasi dengan mengidentifikasi perilaku yang sesuai untuk beberapa situasi. Menurut Darmawan (2010), budaya organisasi adalah norma khas, kepercayaan, prinsip dan cara berperilaku yang bergabung untuk memberikan masing-masing organisasi karakter yang berbeda. Menurut Cushway dan Lodge (2000) budaya organisasi merupakan sistem nilai organisasi dan akan memengaruhi cara pekerjaan dilakukan dan cara para karyawan berperilaku. Budaya organisasi telah dieksplorasi yang berkaitan dengan kepuasan kerja, komitmen organisasi, produktivitas, dan niat berpindah (Lund, 2003). Menurut Robbins dan Judge (2009), budaya organisasi adalah suatu sistem nilai-nilai bersama yang dapat kita perkirakan bahwa karyawan menerima budaya organisasi yang sama meskipun dengan latar belakang yang berbeda di organisasi. O'Reilly et al. (1991) mendefinisikan budaya organisasi adalah pengaturan perilaku, sikap dan nilai.

Menurut Denison (1990), dimensi budaya organisasi dibagi menjadi empat dimensi, yaitu keterlibatan, konsistensi, kemampuan beradaptasi, dan misi. 1) keterlibatan adalah dimensi budaya organisasi yang menunjukkan tingkat karyawan (anggota organisasi) partisipasi dalam proses pengambilan keputusan. 2) konsistensi menunjukkan tingkat kesepakatan anggota dari asumsi dasar organisasi dan nilai-nilai. 3) kemampuan organisasi untuk merespon perubahan internal di organisasi. 4) misi adalah dimensi inti yang menunjukkan tujuan inti dari organisasi yang menyebabkan para anggota di organisasi untuk tabah dan fokus pada apa yang dianggap penting oleh organisasi.

\section{Efikasi Diri}

Istilah efikasi diri dicetuskan oleh Albert Bandura. Teori ini merupakan teori belajar sosial atau teori kognitif sosial. Menurut Bandura (1997), efikasi diri adalah keyakinan yang dimiliki individu tentang kapasitas mereka untuk mengendalikan lingkungan mereka dan memengaruhi jalannya mereka berperilaku, berpikir dan merasakan tentang peristiwa masa depan. Pandangan terhadap efikasi diri memberikan dasar untuk motivasi manusia, dan pencapaian pribadi. Orang-orang cenderung puas dengan pekerjaan mereka ketika mereka merasa 
kompeten untuk melakukan tugas pekerjaan mereka atau mencapai tujuan pekerjaan mereka (Lent et al., 2011). Individu yang memiliki efikasi diri yang tinggi akan mempunyai keyakinan yang lebih kuat dalam kemampuan mereka untuk berhasil melakukan situasi tugas, menetapkan tujuan yang lebih menantang untuk diri mereka sendiri, berinvestasi lebih banyak, bertahan lebih lama dan lebih baik untuk menghadapi pengalaman gagal daripada orang yang rendah efikasi diri (Heuven et al., 2006). Heuven et al. (2006) menemukan bahwa orang dengan tingkat efikasi diri yang tinggi lebih mampu menyelesaikan situasi sulit daripada individu dengan efikasi diri rendah.

Penelitian juga menegaskan bahwa efikasi diri dihubungkan dengan kepuasan kerja karyawan. Pinquart et al. (2003) melaporkan bahwa individu dengan tingkat efikasi diri yang lebih tinggi mengalami tingkat kepuasan kerja yang lebih tinggi. Mereka menemukan bahwa individu dengan keyakinan efikasi diri yang tinggi cenderung tidak memiliki kesenggangan di tempat kerja dan lebih mungkin untuk puas dengan pekerjaan mereka. Penelitian lain juga telah mengkonfirmasi bahwa efikasi diri dihubungkan dengan kepuasan kerja dan memprediksi kepuasan kerja karyawan (Lent dan Brown, 2006; Caprara et al., 2003; Caprara et al., 2006). Penelitian lain menunjukkan hubungan positif yang signifikan antara efikasi diri dan kepuasan, motivasi, afektif dan hasil perilaku dalam pengaturan organisasi (Wood dan Bandura, 1989). Secara khusus, karyawan yang menganggap diri mereka kompeten untuk mempromosikan perubahan dalam proses kerja lebih mungkin untuk membuat penilaian evaluatif positif tentang pekerjaan mereka (Klassen dan Chiu, 2010). Efikasi diri ditemukan berhubungan positif dengan kepuasan kerja baik di dunia barat seperti Kanada dan Amerika Serikat dan negaranegara timur seperti Singapura dan Korea Selatan (Klassen et al., 2009; Lee dan Shin, 2017). Efikasi diri juga memberikan kontribusi terhadap keterlibatan kerja dan kepuasan kerja secara parsial maupun simultan (Høigaard et al., 2012; Perera et al., 2018; Skaalvik dan Skaalvik, 2014). Wang et al. (2015) menemukan bahwa mereka yang memiliki tingkat efikasi diri tinggi akan lebih puas dengan pekerjaan mereka. Bandura (1997) menyatakan bahwa efikasi diri diukur dengan dengan tiga dimensi, yaitu derajat kesulitan tugas (magnitude); keyakinan karyawan terhadap kemampuan diri (generality); tingkat kekuatan karyawan terhadap keyakinan diri (strength).

\section{Kepuasan Kerja Karyawan}

Kepuasan kerja adalah topik yang sangat penting mengenai perilaku organisasi dari perilaku organisasi dan manajemen organisasi. Sejumlah besar model teoritis yang mengintegrasikan beberapa faktor telah dikembangkan dalam literatur kepuasan kerja. Kepuasaan kerja mencerminkan bagaimana seorang pekerja merasakan tentang pekerjaannya serta apa yang seorang pekerja pikirkan tentang pekerjaannya. Menurut Kreitner dan Kinicki (2010) berpendapat bahwa kepuasan kerja adalah respon afektif atau emosional terhadap berbagai aspekdari pekerjaan seseorang. Menurut Darmawan (2016), kepuasan kerja adalah tingkat perasaaan menyenangkan yang diperoleh dari penilaian pekerjaan seseorang atau pengalaman kerja. Kepuasan kerja dimaknai tentang sejauh mana orang menyukai pekerjaan secara keseluruhan atau sehubungan dengan kondisi atau penghargaan tertentu (Spector, 1997). Kepuasan kerja telah dikonseptualisasikan sebagai reaksi afektif dan penilaian kognitif dari pekerjaan mereka sehari-hari (Ho dan Au, 2006; Skaalvik dan Skaalvik, 2010). Lent dan Brown (2006) mengkonseptualisasikan kepuasan kerja sebagai variabel kunci yang menyusun model termasuk a) kepuasan kerja-pembelajaran; b) kepribadian dan sifat afektif; c) tujuan dan aktivitas yang berorientasi pada tujuan; d) efikasi diri; e) kondisi kerja dan hasil; dan f) dukungan lingkungan, sumber daya dan hambatan yang berorientasi pada tujuan.

Jika karyawan menunjukkan sikap positif terhadap pekerjaan itu menunjukkan bahwa mereka puas dengan pekerjaan itu (Sekaran, 1989). Kepuasan kerja adalah hal dasar yang menunjukkan jalan menuju pengakuan, gaji, promosi, dan pencapaian tujuan yang memenuhi keinginan mereka. (Kaliski, 2007). Orangorang memiliki perilaku yang berbeda tentang pekerjaan mereka seperti berbagai jenis pekerjaan yang mereka lakukan rekan kerja, supervisor dan gaji mereka (George et al., 2008). Kepuasan kerja menunjukkan persepsi seseorang bahwa pekerjaan mampu memenuhi keinginan material dan psikologis (Aziri, 2008). Menurut Luthans (2011) ada beberapa faktor penentu kepuasan kerja karyawan, yaitu 1) pekerjaan itu sendiri; 2) gaji atau imbalan yang dirasakan adil; 3) promosi; 4) pengawasan (supervisi); 5) rekan kerja. 
Hipotesis dalam penelitian ini adalah:

1. Variabel budaya organisasi dan efikasi diri mempunyai pengaruh simultan terhadap kepuasan kerja

2. Dari kedua variabel yang diteliti, variabel efikasi diri berpengaruh dominan terhadap kepuasan kerja.

\section{METODOLOGI PENELITIAN}

Variabel dalam penelitian ini meliputi:

1. Variabel bebas (independent variable)

Variabel bebas $(\mathrm{X})$ yaitu variabel yang nilainya mempengaruhi nilai variabel lain, atau variabel yang menjadi sebab timbulnya atau berubahnya variabel dependent / variabel terikat (Sugiyono, 2015: 52). Dalam penelitian ini yang termasuk dalam variabel bebas adalah budaya kerja dan efikasi diri.

2. Variabel terikat (dependent variable)

Variabel terikat (Y) yaitu variabel yang dipengaruhi atau menjadi akibat karena adanya variabel bebas (Sugiyono, 2015: 52). Dalam penelitian ini yang termasuk dalam variabel terikat adalah kepuasan kerja.

Penelitian ini dilakukan di perusahaan $\mathrm{X}$ sebagai perusahaan swasta yang bergerak di bidang jasa penyewaan dan pengelolaan gudang serta proses pengiriman barang. Perusahaan yang digunakan di penelitian ini merupakan salah satu kantor dari PT. X yang berada di Kota Surabaya. Jenis data yang diambil, yaitu data primer data primer merupakan data yang langsung dikumpulkan oleh peneliti. Data tersebut diperoleh dari responden melalui kuesioner tentang variabel yang diteliti, yaitu variabel budaya organisasi, efikasi diri, dan kepuasaan kerja dengan memberikan pertanyaan kepada responden. Data primer diperoleh melalui kuesioner berbentuk skala likert kepada karyawan yang berjumlah 86 orang sehingga menggunakan teknik sampel jenuh. Teknik analisis data adalah analisis regresi linear berganda dengan bantuan program SPSS 26.0. Selain itu juga dilakukan uji validitas, uji reliabilitas, uji asumsi klasik yang didalamnya terdapat beberapa pengujian yang terdiri dari uji normalitas, uji autokorelasi, uji heteroskedastisitas, dan uji multikolinieritas. Uji kelayakan data tersebut dilanjutkan dengan uji hipotesis yang terdiri dari uji t.

\section{HASIL PENELITIAN}

Dari data 86 responden yang terkumpul dilakukan penggambaran karakteristik responden yang ditunjukkan seperti pada Tabel 1 berikut ini.

Berdasarkan Tabel 1 dapat diketahui bahwa karakteristik responden yang dominan adalah kelompok pria sebanyak 55,8\%; kelompok rentang usia 20 - 40 tahun sebesar 75,6\%; kelompok responden dengan masa kerja $1-5$ tahun sebesar $47,7 \%$.

Tabel 1

Karakteristik Responden Berdasarkan Jenis Kelamin \& Usia

\begin{tabular}{|c|c|c|c|c|}
\hline No & & Karakteristik & Jumlah Responden & Presentase \\
\hline \multirow{2}{*}{1} & \multirow{2}{*}{ Jenis Kelamin } & Pria & 48 & $55,8 \%$ \\
\hline & & Wanita & 38 & $44,2 \%$ \\
\hline \multirow{5}{*}{2} & \multirow{5}{*}{ Usia } & $<20$ tahun & 2 & $2,3 \%$ \\
\hline & & 20-30 Tahun & 31 & $36,1 \%$ \\
\hline & & 31-40 Tahun & 34 & $39,5 \%$ \\
\hline & & 41-50 Tahun & 15 & $17,4 \%$ \\
\hline & & $>50$ Tahun & 4 & $4,7 \%$ \\
\hline \multirow{4}{*}{3} & \multirow{4}{*}{ Masa Kerja } & $<1$ tahun & 13 & $15,1 \%$ \\
\hline & & $1-5$ tahun & 41 & $47,7 \%$ \\
\hline & & $5-10$ tahun & 20 & $23,3 \%$ \\
\hline & & $>10$ tahun & 12 & $14,0 \%$ \\
\hline \multicolumn{3}{|c|}{ Total } & 86 & $100 \%$ \\
\hline
\end{tabular}

Sumber output SPSS 
Uji validitas dilakukan dengan mengamati nilai koefisien antara item dengan total item sama atau di atas 0,3 sehingga item tersebut dinyatakan valid tetapi jika nilai korelasinya di bawah 0,3 maka item tersebut dinyatakan tidak valid. Tabel 2 menunjukkan hasil uji validitas semua penelitian. Tabel 2 menunjukkan bahwa seluruh item pertanyaan nilai corrected item total correlation di atas 0,3 dan disimpulkan bahwa semua butir pertanyaan untuk variabel penelitian adalah valid.

Tabel 2

Uji Validitas Variabel Penelitian

\begin{tabular}{|c|c|c|c|}
\hline No & Variabel & Pertanyaan & Nilai \\
\hline 1 & \multirow{8}{*}{$\begin{array}{l}\text { Budaya } \\
\text { Organisasi } \\
\text { (X1) }\end{array}$} & Pekerjaan yang saya tekuni sesuai dengan prinsip hidup & 0,634 \\
\hline 2 & & Saya berusaha menyelesaikan pekerjaan sebaik mungkin & 0,605 \\
\hline 3 & & $\begin{array}{l}\text { Saya memahami bahwa mengabaikan tata nilai inti organisasi akan } \\
\text { membawa saya kepada kesulitan }\end{array}$ & 0,679 \\
\hline 4 & & Saya mengetahui tata nilai inti organisasi & 0,692 \\
\hline 5 & & Saya mengetahui kode etik organisasi & 0,706 \\
\hline 6 & & Saya merasa strategi perusahaan yang dilaksanakan akan berhasil. & 0,748 \\
\hline 7 & & Pimpinan saya memiliki sudut pandang pemikiran jangka panjang. & 0,607 \\
\hline 8 & & Visi organisasi mampu menciptakan motivasi bagi karyawan & 0,773 \\
\hline 9 & \multirow{6}{*}{$\begin{array}{c}\text { Efikasi } \\
\text { Diri } \\
\text { (X2) }\end{array}$} & Saya memiliki pandangan positif terhadap tugas yang dikerajakan & 0,729 \\
\hline 10 & & Saya memiliki keyakinan diri pada seluruh proses pekerjaan & 0,736 \\
\hline 11 & & Saya mampu menyikapi suatu keadaan yang beragam dengan sikap positif & 0,787 \\
\hline 12 & & Saya berusaha tekun pada setiap pekerjaan yang diberikan & 0,658 \\
\hline 13 & & Saya tidak mudah menyerah untuk menyelesaikan hambatan & 0,716 \\
\hline 14 & & Saya memiliki komitmen untuk menyelesaikan tugas & 0,635 \\
\hline 15 & \multirow{10}{*}{$\begin{array}{c}\text { Kepuasan } \\
\text { Kerja } \\
\text { (Y) }\end{array}$} & Saya sangat senang dengan pekerjaan saya & 0,691 \\
\hline 16 & & Saya merasa senang bila pekerjaan saya terselesaikan dengan hasil baik & 0,538 \\
\hline 17 & & Gaji saya sesuai dengan tanggung jawab pekerjaan & 0,599 \\
\hline 18 & & Saya merasa puas dengan gaji yang saya terima & 0,495 \\
\hline 19 & & Saya memiliki rekan-rekan kerja yang ramah & 0,650 \\
\hline 20 & & $\begin{array}{l}\text { Saya senang bekerja dengan rekan kerja yang saling membantu } \\
\text { menyelesaikan pekerjaan }\end{array}$ & 0,682 \\
\hline 21 & & Perusahaan memberikan promosi jabatan sesuai dengan kinerja karyawan & 0,708 \\
\hline 22 & & Ada kesempatan promosi secara adil kepada seluruh karyawan & 0,782 \\
\hline 23 & & Saya merasa puas dengan atasan saat menangani masalah & 0,553 \\
\hline 24 & & Saya senang dengan atasan yang memperlakukan bawahan dengan baik & 0,395 \\
\hline
\end{tabular}

Sumber output SPSS

Uji reliabilitas untuk mengukur suatu kuesioner yang merupakan indikator dari suatu variabel Pengukuran reliabilitas penelitian ini dilakukan dengan uji statistik Cronbach Alpha dengan ketentuan handal bila nilai cronbach's alpha $>0,60$. Tabel 3 menunjukkan hasil uji tersebut.

Tabel 3

Hasil uji reliabilitas

\begin{tabular}{|c|l|c|c|}
\hline No & \multicolumn{1}{|c|}{ Variabel } & Cronbach's Alpha & Status \\
\hline 1 & Budaya Organisasi (X1) & 0,822 & Reliabel \\
\hline 2 & Efikasi Diri (X2) & 0,793 & Reliabel \\
\hline 3 & Kepuasaan Kerja (Y) & 0,697 & Reliabel \\
\hline
\end{tabular}

Sumber output SPSS

Dari hasil uji reliabilitas diketahui nilai korelasi koefisien cronbach's alpha > 0,6 sehingga variabel budaya organisasi (X1), efikasi diri (X2), dan kepuasan kerja (Y) dinyatakan reliabel dan berkualitas digunakan sebagai instrumen penelitian karena handal.

Uji normalitas untuk mengetahui sebaran distribusi. Penelitian ini menggunakan metode dengan melihat normal probability plot. Model Regresi yang baik adalah data distribusi normal atau mendekati normal, untuk mendeteksi normalitas dapat dilakukan dengan melihat penyebaran data (titik) pada sumbu diagonal grafik. 


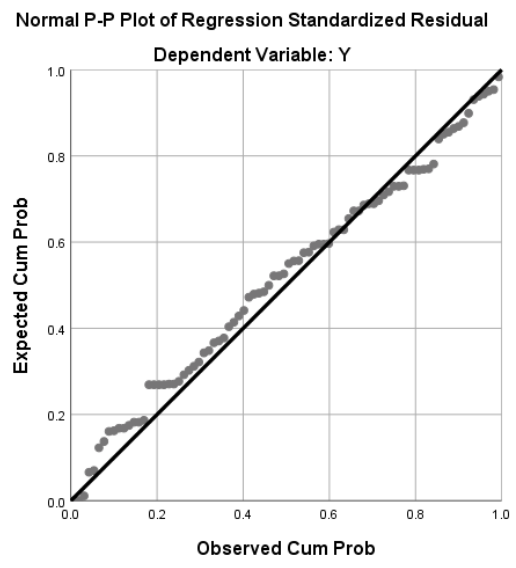

Gambar 1

Hasil Uji Normalitas

Sumber output SPSS

Dari grafik P-P Plot dapat dilihat bahwa titik-titik menyebar di sekitar garis diagonal dan penyebarannya mengikuti arah garis diagonal. Dengan demikian, data yang digunakan pada penelitian ini memenuhi asumsi normalitas.

Uji autokorelasi dilakukan dengan uji Durbin-Watson (D-W) untuk mendeteksi ada atau tidaknya korelasi antara kesalahan pengganggu pada periode $t$ dengan kesalahan pengganggu pada periode $t-1$ (sebelumnya). Dari output SPSS diperoleh nilai DW sebesar 1,359 dan berada di rentang 1,11 dan 1,54 sehingga dinyatakan tanpa kesimpulan menyikapi adanya autokorelasi pada model regresi. Meski demikian akan diperkuat dengan uji asumsi lainnya.

Uji heteroskedastisitas dilakukan dengan pengamatan pada gambar scatter plot dengan ketentuan bila ada pola tertetu, seperti titik-titik yang ada membentuk pola tertentu yang teratur (bergelombang, melebar kemudian menyempit), maka mengindikasikan telah terjadi heteroskedastisitas. Sebalilknya bila tidak ada pola yang jelas, serta titik-titik menyebar di atas dan di bawah angka 0 pada sumbu Y, maka tidak terjadi heteroskedastisitas.

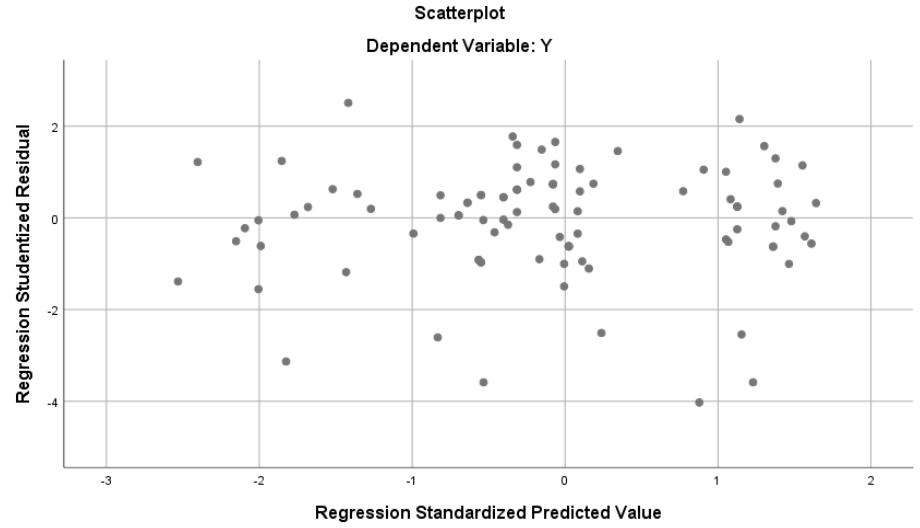

Gambar 2

Hasil Uji Heteroskedastisitas

Sumber output SPSS

Berdasarkan scatterplot dapat diketahui bahwa titik-titik menyebar secara acak serta penyebarannya terletak di atas maupun di bawah angka 0 pada sumbu Y, maka hal ini dapat disimpulkan bahwa tidak terjadi heteroskedastisitas.

Uji multikolinieritas bertujuan untuk menguji apakah model regresi ditemukan adanya korelasi antar variabel bebas. Model regresi yang baik seharusnya tidak terjadi korelasi di antara variabel bebas. Uji mutikolinieritas berpedoman kepada Variance Inflation Factors (VIF) < 10 untuk dikatakan tidak terjadi multikolinearitas. VIF dari hasil output SPSS sebesar 7,264 sehingga terbukti tidak ada gejala multikolinieritas. 
Dengan demikian secara keseluruhan berdasarkan uji validitas, reliabilitas dan asumsi klasik, kualitas data yang terkumpul telah layak untuk diproses lebih lanjut.

Untuk mengetahui masing-masing pengaruh variabel bebas terhadap variabel terikat dilakukan uji t dengan ketentuan nilai Sig <0,05. Berdasarkan Tabel 4 diketahui hasil uji t menunjukkan nilai Sig kurang dari 0,05 sehingga disimpulkan variabel budaya organisasi (X1) dan efikasi diri (X2) berpengaruh signifikan secara parsial terhadap kepuasan kerja (Y).

Tabel 4

Uji t

\begin{tabular}{|c|c|c|c|c|c|c|c|}
\hline \multirow[t]{2}{*}{ Model } & \multicolumn{2}{|c|}{$\begin{array}{l}\text { Unstandardized } \\
\text { Coefficients }\end{array}$} & \multirow{2}{*}{$\begin{array}{c}\begin{array}{c}\text { Standardized } \\
\text { Coefficients }\end{array} \\
\text { Beta }\end{array}$} & \multirow[t]{2}{*}{$\mathrm{t}$} & \multirow[t]{2}{*}{ Sig } & \multicolumn{2}{|c|}{ Collinearity Statistics } \\
\hline & $\mathrm{B}$ & Std. Error & & & & Tolerance & VIF \\
\hline (Constant) & 6.939 & 2.069 & & 3.354 & .001 & & \\
\hline $\mathrm{X} 1$ & .548 & .092 & .461 & 5.930 & .000 & .138 & 7.264 \\
\hline $\mathbf{X} 2$ & .660 & .099 & .521 & 6.694 & .000 & .138 & 7.264 \\
\hline
\end{tabular}

Sumber output SPSS

Berdasarkan Tabel 4, persamaan Regresi yang diperoleh adalah $\mathrm{Y}=6,939+0,548 \mathrm{X} 1+0,660 \mathrm{X} 2+\mathrm{e}$. Persamaan tersebut memiliki makna variabel X1 (budaya organisasi) dan X2 (efikasi diri) memiliki arah hubungan yang positif terhadap variabel Y (kepuasan kerja). Peningkatan kedua variabel bebas menyebabkan peningkatan variabel terikat. Variabel efikasi diri adalah variabel yang berpengaruh dominan terhadap variabel kepuasan kerja.

Sebagai tambahan dari hasil output SPSS juga ditunjukkan hasil uji F untuk mengetahui pengaruh simultan variabel bebas yang dimasukkan pada model penelitian terhadap variabel terikat. Dengan ketentuan nilai Sig < 0,05 untuk menunjukkan pengaruh yang signifikan. Hasil ditunjukkan pada Tabel 5 berikut ini.

Tabel 5

Uji F

\begin{tabular}{|c|l|r|r|r|r|}
\hline Model & Sum of Squares & df & Mean Square & F & Sig. \\
\hline 1 & Regression & 4746.418 & 2 & 2373.209 & 558.263 \\
\hline & Residual & 352.838 & 83 & 4.251 & \\
\hline & Total & $\mathbf{5 0 9 9 . 2 5 6}$ & $\mathbf{8 5}$ & & \\
\hline
\end{tabular}

Sumber output SPSS

Berdasarkan hasil pengujian diperoleh nilai signifikan $0,000<0,05$ menunjukkan arti bahwa variabel bebas (budaya organisasi dan efikasi diri) secara simultan memiliki pengaruh signifikan terhadap variabel terikat (kepuasan kerja). Untuk mengetahui besaran kontribusi variabel bebas terhadap pembentukan variabel terikat dapat dilihat pada Tabel 6.

Tabel 6

Koefesien Determinasi

\begin{tabular}{|l|l|l|l|l|l|}
\hline Model & $\mathrm{R}$ & R Square & $\begin{array}{l}\text { Adjusted R } \\
\text { Square }\end{array}$ & $\begin{array}{l}\text { Std. Error of the } \\
\text { Estimate }\end{array}$ & Durbin-Watson \\
\hline 1 & $.965 \mathrm{a}$ & .931 & .929 & 2.062 & 1.359 \\
\hline
\end{tabular}

Sumber output SPSS

Nilai koefisien determinasi adalah antara nol dan satu. Nilai $\left(\mathrm{R}^{2}\right)$ yang kecil berarti adanya kemampuan terbatas variabel bebas menjelaskan variasi variabel terikat. Tabel 6 menunjukkan nilai koefesien determinasi atau $\mathrm{R}$ square adalah 0,931 . Nilai $\mathrm{R}$ square 0,931 mengandung arti bahwa variabel bebas memberikan kontribusi sebesar 93,1\% terhadap pembentukan variabel kepuasan kerja, sedangkan sisanya 6,9\% dipengaruhi oleh variabel lain di luar persamaan regresi ini atau variabel yang tidak diteliti. 


\section{PEMBAHASAN}

Berdasarkan hasil analisis data membuktikan bahwa variabel budaya organisasi memiliki pengaruh positif dan signifikan terhadap kepuasan kerja. Hal ini menunjukkan bahwa semakin baiknya budaya organisasi dan dihayati oleh karyawan maka akan membentuk kepuasan kerja. Temuan ini sejalan dengan hasil penelitian sebelumnya (Lok dan Crawford, 2004; Chang dan Lee, 2007; Darmawan, 2016; Tumbeleka et al., 2016). Dari temuan tersebut menunjukkan budaya organisasi memiliki dampak yang kuat dan mendalam untuk membantu karyawan merasa puas dengan pekerjaan yang selanjutnya dari kepuasan tersebut, organisasi dapat berharap untuk memperoleh peningkatan kinerja dan produktivitas karyawan. Di perusahaan yang diteliti adalah mudah untuk mengembangkan organisasi dengan cara yang positif ketika setiap karyawan berada di jalur yang benar. Hal ini karena para karyawan pada umumnya memiliki pemahaman tentang budaya organisasi dan memperlihatkan resapan nilai-nilai yang terkandung dalam budaya organisasi ke dalam perilaku kerja. Meski sebenarnya setiap karyawan yang bekerja di organisasi memiliki norma dan nilai masing-masing serta keyakinan yang berbeda terhadap organisasi tempatnya bekerja. Untuk memperkuat budaya organisasi, para karyawan baru perlu untuk mengadopsi budaya organisasi dan memahami tentang keunggulan bersaing.

Selain itu temuan lain di penelitian ini adalah efikasi diri terbukti memiliki pengaruh yang signifikan terhadap kepuasan kerja. Temuan ini sesuai dengan studi sebelumnya dari beberapa peneliti (Wood dan Bandura, 1989; Pinquart et al., 2003; Caprara et al., 2003; Caprara et al., 2006; Luthans et al., 2006; Lent dan Brown, 2006; Klassen et al., 2009; Klassen dan Chiu, 2010; Lent et al., 2011; Høigaard et al., 2012; Skaalvik dan Skaalvik, 2014; Wang et al., 2015; Lee dan Shin, 2017; Perera et al., 2018). Efikasi diri secara umum akan memengaruhi kepuasan kerja melalui hubungannya dengan keberhasilan praktis dalam pekerjaan (Judge dan Bono, 2001). Berdasarkan pandandan dari teori kognitif sosial, efikasi diri menunjukkan keyakinan karyawan tentang kemampuan mereka memberikan perubahan untuk hasil yang diinginkan berdasarkan kerja keras mereka. Perilaku karyawan dipengaruhi oleh harapan hasil dan efikasi. Ekspektasi hasil mengacu pada penilaian yang dibuat individu tentang kemungkinan perilaku yang akan mengarah pada hasil tertentu dalam situasi atau konteks tertentu. Namun, individu tidak akan menghasilkan perilaku seperti itu kecuali mereka memegang keyakinan bahwa mereka mampu melakukannya, yaitu harapan untuk berhasil. Hasil penelitian ini membuktikan adanya keyakinan karyawan terhadap kemampuan diri sendiri akan memberikan dampak positif terhadap kepuasan kerja.

\section{KESIMPULAN DAN SARAN}

Hasil penelitian membuktikan bahwa budaya organisasi memiliki pengaruh terhadap kepuasan kerja secara signifikan. Selain itu, efikasi diri juga berpengaruh signifikan terhadap kepuasan kerja. Begitu pun pengaruh variabel bebas secara simultan, juga signifikan. Variabel efikasi diri menjadi variabel yang berpengaruh dominan terhadap kepuasan kerja.

Beberapa saran untuk kepentingan pengembangan perusahaan adalah mengamati lebih lanjut mengenai intepretasi karyawan perihal budaya organisasi. Setiap karyawan memiliki norma dan nilai serta keyakinan yang berbeda terhadap organisasi tempatnya bekerja. Kesesuaian yang keduanya akan memperkuat budaya organisasi sedangkan perbedaan harus diminimalisir untuk mencegah perbedaan di masa mendatang. Setiap kali karyawan baru bergabung dengan organisasi harus didorong untuk menyesuaikan norma dan nilai diri dengan budaya organisasi. Kurangnya sosialisasi perusahaan pada karyawan baru, pola pembinaan bawahan, pola perilaku dan pola interaksi tidak dapat membentuk budaya organisasi yang kuat dan tidak dapat meningkatkan kepuasaan kerja pada karyawan. Meski demikian kebijakan organisasi mengenai budaya harus jelas untuk memahami karyawan. Perilaku karyawan terhadap pekerjaan dan organisasinya dipengaruhi oleh kebijakan dan budaya organisasi. Organisasi harus memiliki budaya yang fleksibel dan manajemen puncak harus menggunakan teknik manajemen yang terdesentralisasi sehingga karyawan di tingkat bawah memiliki wewenang dan kekuatan untuk mengambil keputusan tentang masalah apa pun yang mereka hadapi sesuai dengan wewenangnya. Setiap karyawan harus memiliki hubungan langsung dengan manajemen tingkat atas. Hal ini akan berdampak positif pada tingkat kepuasan mereka serta kinerja karyawan yang akan meningkatkan produktivitas organisasi.

Selain itu untuk memperkuat efikasi diri, organisasi harus memberikan solusi untuk masalah yang dihadapi karyawan dalam pekerjaan karena jika ada karyawan yang menghadapi masalah pada setiap tahap dan 
memiliki beberapa ambiguitas mengenai beberapa operasi, organisasi harus memiliki beberapa kebijakan yang jelas untuk menyelesaikan masalah karyawan, jika tidak hal ini akan menciptakan ambiguitas pada karyawan dan akan berdampak negatif terhadap kepuasan kerja mereka. Adanya kerjasama tim di antara karyawan di organisasi itu akan meningkatkan kepuasan kerja karyawan.

\section{DAFTAR PUSTAKA}

Aziri, B. (2008). Human Resource Management, Unemployment Satisfaction and employee Motivation, Gostivar: Tringa Design.

Bandura, A. (1997). Self-efficacy: The Exercise of Control. New York: W.H. Freeman.

Caprara, G.V., C. Barbaralli, L. Borgogni, \& P. Steca. (2003). Efficacy Beliefs as Determinants of Teachers Job Satisfaction, Journal of Educational Psychology, 95, 621-832.

Caprara, G. V., Barbaranelli, C., Steca, P., \& Malone, P. S. (2006). Teachers' Self-efficacy Beliefs as Determinants of Job Satisfaction and Students' Academic Achievement: A Study at the School Level, Journal of School Psychology, 44(6), 473-490.

Chang, S. \& Lee, M. (2007). A Study on Relationship among Leadership, Organizational Culture, the Operation of Learning Organization and Employees' Job Satisfaction, The Learning Organization, 14(2), 155185 .

Cushway, B., \& Lodge, D. (2000). Organizational Behaviour and Design. Crest Pub House.

Darmawan, D. (2007). Budaya Organisasi dan Pengaruhnya terhadap Kebebasan Pengambilan Keputusan Manajerial, Jurnal Media Komunikasi Ekonomi dan Manajemen, 5(2), 40-53.

Darmawan, D. (2010). Budaya Organisasi, Surabaya: Metromedia.

Darmawan, D. (2016). Peranan Motivasi Kerja, Komitmen Organisasi dan Budaya Organisasi terhadap Kepuasan Kerja, Jurnal Ilmiah Manajemen Pendidikan Indonesia, 2(3), 109-118.

Darmawan, D. (2010). Pengaruh Kompetensi Kerja, Budaya Organisasi, Kepemimpinan dan Kompensasi terhadap Loyalitas Kerja, Jurnal Ilmu Sosial, 4(2), 63-76.

Denison, D. R. (1990). Corporate Culture and Organizational Effectiveness, New York: John Wiley \& Sons.

Deshpande, R., \& Webster, F. E. (1989). Organizational Culture and Marketing: Defining the Research Agenda. Journal of Marketing, 53(1), 3-15.

George, J.M. \& Jones, G.R. (2008). Understanding and Managing Organizational behavior, New Yersey: Pearson/Prentice Hall.

Heuven, E., Bakker, A.B., Schaufeli, W.B., \& Huisman, N. (2006). The Role of Self-efficacy in Performing Emotion Work, Journal of Vocational Behavior, 69 (2), 222-235.

Ho, C. L., \& Au, W. T. (2006). Teaching Satisfaction Scale: Measuring Job Satisfaction of Teachers. Educational and Psychological Measurement, 66(1), 172-185.

Høigaard, R., Giske, R., \& Sundsli, K. (2012). Newly Qualified Teachers' Work Engagement and Teacher Efficacy Influences on Job Satisfaction, Burnout, and the Intention to Quit. European Journal of Teacher Education, 35(3), 347-357.

Judge, T.A., \& Bono, J. E. (2001). Relationship of Core Self-Evaluations Traits-Self-Esteem, Generalized Self-effeicacy, Locus of Control, and Emotional Stability-With Job Satisfaction and Job Performance: A Meta Analysis, Journal of Applied Psychology, 86, 80-92. 
Kaliski, B.S. (2007). Encyclopedia of Business and Finance, Detroit: Thompson Gale.

Klassen, R. M., Bong, M., Usher, E. L., Chong, W. H., Huan, V. S., Wong, I. Y. F., \& Georgiou, T. (2009). Exploring the Validity of a Teachers' Self-efficacy Scale in Five Countries. Contemporary Educational Psychology, 34(1), 67-76.

Klassen, R. M., \& Chiu, M. M. (2010). Effects on Teachers' Self-efficacy and Job Satisfaction: Teacher Gender, Years of Experience, and Job Stress. Journal of Educational Psychology.

Kreitner, Robert \& Kinnichi, Angelo. (2010). Organizational Behaviour. New York : McGraw-Hill Irwin.

Lee, E. S., \& Shin, Y. J. (2017). Social Cognitive Predictors of Korean Secondary School Teachers' job and Life Satisfaction. Journal of Vocational Behavior, 102, 139-150.

Lent, R.W., \& S.D. Brown. (2006). Integrating Person and Situation Perspectives on Work Satisfaction: A Social-cognitive View, Journal of Vocational Behavior, 69, 236-247.

Lent, R.W., Nota, L., Soresi, S., Ginevra, M.C. Duffy, R.D., R.D., \& Brown, S.D. (2011). Predicting the Job and Life Satisfaction of Italian Teachers: Test of a Social Cognitive Model, Journal of Vocational Behavior, 79, 91-97.

Lok, P. \& Crawford, J. (2004). The effect of Organizational Culture and Leadership Style on Job Satisfaction and Organizational Commitment: A Cross National Comparison. Journal of Management Development, 23 (4), 321- 338.

Lund, D. B. (2003). Organizational Culture and Job Satisfaction. Journal of Business \& Industrial Marketing, 18(3), 219-236.

Luthans, F., Zhu, W., \& Avolio, B.J. (2006). The Impact of Efficacy on Work Attitudes Across Cultures, Journal of World Business, 41, 121-132.

Luthans, Fred. (2011). Organizational Behavior: An Evidence-based Approach, New York : McGraw-Hill Irwin.

O'Reilly, C. A., Chatman, J. A., \& Caldwell, D. F. (1991). People and Organizational Culture: A Profile Comparison Approach to Assessing Person-Organization Fit. Academy of Management Journal, 34 (3), 487-516.

Perera, H. N., Granziera, H., \& McIlveen, P. (2018). Profiles of Teacher Personality and Relations with Teacher Self-efficacy, Work Engagement, and Job Satisfaction. Personality and Individual Differences, 120, 171-178.

Pettigrew, A. (1979). Studying Organizational Culture. Administrative Science Quarterly, 24, 570-581.

Pinquart, M., Juang, L.P., \& Silbereisen, R.K. (2003). Self-efficacy and Succesfull School-to-work: Transition: A Longitudinal Study, Journal of Vocational Behavior, 63(3), 329-346.

Raghuram, S., Wiesenfeld, B., \& Garud, R., (2003). Technology Enabled Work: the Role of Self-efficacy in Determining Telecommuter Adjustment and Structuring Behavior, Journal of vocational Behavior, 63, $180-198$.

Ravasi, D., \& Schultz, M. (2006). Responding to Organizational Identity Threats: Exploring the role of Organizational Culture, Academy of Management Journal, 49(3), 1-59.

Robbins, Stephen P. \& Timothy A. Judge. (2009). Organizational Behavior, USA: Pearson International Edition, Prentice -Hall.

Santosa, Aditya \& D. Darmawan. (2002). Hubungan Kepemimpinan, Budaya Organisasi dan Kinerja Karyawan, Jurnal Ilmu Manajemen, 3(2), 81-92. 
Schneider, B. \& Reichers, A.E. (1983). On the Etiology of Climates. Personnel Psychology, 36, 19-39.

Sekaran, U. (1989). Paths to the Job Satisfaction of Bank Employees. Journal of Organizational Behavior, 10(4), 6-12.

Skaalvik, E. M., \& Skaalvik, S. (2010). Teacher Self-efficacy and Teacher Burnout: A study of Relations. Teaching and Teacher Education, 26(4), 1059-1069.

Skaalvik, E. M., \& Skaalvik, S. (2014). Teacher Self-efficacy and Perceived Autonomy: Relations with Teacher Engagement, Job Satisfaction, and Emotional Exhaustion. Psychological Reports, 114(1), 68-77.

Spector, P. E. (1997). Job satisfaction: Application, assessment, causes and consequences, Thousand Oaks, CA: Sage Publications, Inc.

Tumbelaka, S. S. X., Alhabsji, T. \& Nimran, U. (2016). Pengaruh Budaya Organisasi Terhadap Kepuasan Kerja, Komitmen Organisasional dan Intention to Leave, Jurnal Bisnis dan Manajemen, 3(1), 94-108.

Wood, R., \& Bandura, A., (1989). Social Cognitive Theory of Organizational Management, Academy of Management Review, 14, 361-384.

Wang, H., Hall, N. C., \& Rahimi, S. (2015). Self-efficacy and Causal Attributions in Teachers: Effects on Burnout, Job Satisfaction, Illness, and Quitting Intentions. Teaching and Teacher Education, 47, 120-130. 